\title{
Design of Multilayered Cellulose Molds-Lignophenol Composites
}

\author{
Mitsuru Aoyagi, Takashi Naito and Masamitsu Funaoka \\ Graduate School of Bioresources, Mie University, Japan Science and Technology Agency (JST), \\ Solution Oriented Research of Science and Technology (SORST) \\ Fax: +81-59-231-9517, e-mail: aoyagi@bio.mie-u.ac.jp
}

Birch (Betula maximowicziana)-lignophenol ( $p$-cresol type, lignophenol) has been directly derived from native lignin through the phase-separation system composed of concentrated acid and phenol under mild condition. Composites of lignophenol and cellulose mold already have been well discussed as application of lignophenol. In this study, strength and stability of composites of lignophenol and cellulose fiber molds prepared from pulps with three different freeness (F100, F400 and F700) have studied. The relationship between the freeness of pulp and physical property of resulting mold was discussed. In general, single layer mold had high strength and stability. But laminated mold with blended layer as buffer (F100/F400/F100) had higher mechanical properties than other molds without buffers. For example, modulus of rupture (MOR) and modulus of elasticity (MOE) of a F100/F400/F100 laminated mold were $73.4 \mathrm{MPa}$ and 4.07 GPa, respectively. Moreover, all composites had high water resistance and strength because of both hydrophobic properties and coagulation force of lignophenol.

Key words: lignin, lignophenol, cellulose mold, lamination

\section{INTRODUCTION}

Lignocellulosics have complicated three dimensional inter-penetrating network type structures composed of cellulose and lignin. By delignification in the process of pulping, pulp was obtained from lignocellulosics. Papers are composed of the fibers strongly aggregated by rich hydrogen bonding. Therefore papers were disintegrated in water. In this way, recycling of paper was carried out. In the recycle process of paper, by beating treatment on pulp, intensity of fiber was increased by both external and internal fibrillation. By external fibrillation, frame work structure was soften and fluffed. Moreover by internal fibrillation, second cell wall ( $\mathrm{S} 1, \mathrm{~S} 2$ and $\mathrm{S} 3$ ) layers were destroyed. Then water easily penetrated into the broken cell wall. The swelling and plasticizing cell realized an increase of surfaces (Fig.1).

But after repeated beating, total intensity of pulp decreased by the increase of crystallinity with prior external fibrillation of amorphous regions, decrease of swelling because destruction of structures of high degree on pulp. occurred. Therefore recycling of paper was achieved 3-4 times at most. Then waste paper was generally burned out to $\mathrm{CO}_{2}$, because these damaged pulps were not suitable for papers.

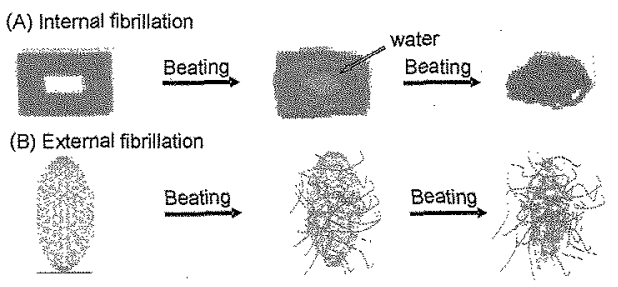

Fig.1 Disintegration of pulp by beating in water. (A) Internal fibrillation of a cell wall and (B) external fibrillation of a frame work structure of pulp.
However these damaged frame-work structures of pulp (Fig.2B) contributed to enforcement of pulp molds because three-dimensional interaction occurred. A degree of pulp was estimated by freeness. Freeness was an indicator for a degree of fibrillation of pulp estimated by storage of water [1]. For example, freeness of virgin pulp without fibrillation is $c a$. 700 , but a recycled paper shows lower value.

Although strong molds were obtained by these preparation ways in fact, these pulp molds were also weak for water. By compositing with lignophenol, which is directly synthesized from lignocellulosics through the phase-separation system [2-6], the resulting composite got high hydrophobicity and strength. Both lignophenol and pulp have high recyclability and sustainability by easy conversion into raw materials for chemical industries from phytomass re-produced by photosynthesis. Therefore the composites are expected to be used as highly recyclable materials.

In this study, to improve the properties of both these pulp molds and lignophenol-pulp mold composites, designs of laminating pulp mold with different freeness values were discussed.

\section{EXPERIMENTAL}

2.1 Preparation of pulp

Copy paper (500 g) containing $70 \%$ of recycled paper (KBK-39N, KOKUYO Co. was dispersed in de-ionized water. After $24 \mathrm{hrs}$, the suspension was disintegrated for $20 \mathrm{~min}$ with $2000 \mathrm{rpm}$ rotation. The $2.5 \%$ dispersion of disintegrated pulp (20-L) was beaten to freeness 100 or 400 using Niagara beater (Kumagai Riki Kogyo Co.). Freeness of pulp was estimated using Canadian freeness tester [1]. The value of freeness was the average of 4 times measurements. After drying on the $\mathrm{P}_{2} \mathrm{O}_{5}, \mathrm{BET}$ surface area was measured by Surface Area and Poresize 


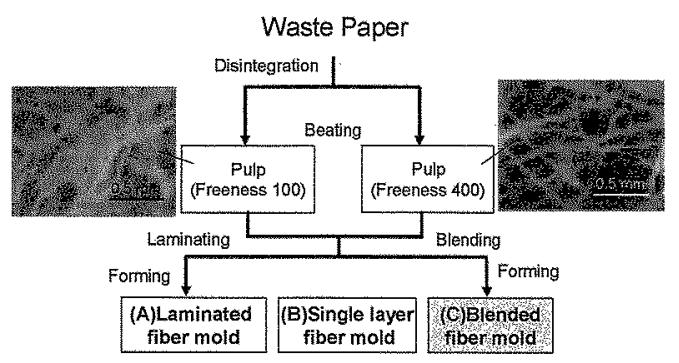

Fig. 2 Preparation of (A) laminated fiber mold, (B) single layer fiber mold and $(C)$ blended fiber mold from waste paper through disintegration and beating in water.

Analyzer NOVA 4200e (Quantachrome Inc.).

\subsection{Preparation of pulp mold}

The dispersion of pulp was quietly immersed into molding frame. The resulting wet fiber mat was dried at $60{ }^{\circ} \mathrm{C}$ for 2 days. Then the dry mat was following pressed under $50{ }^{\circ} \mathrm{C}$ for self-contraction of pulp by shape-control machine (Yamamoto Eng. Works Co.). This process was only to keep the flat of the mold but not to force the shape of the mold change by pressure or heating. The mold was shaped by only aggregation by interactions of pulps. Six types of molds were prepared with different combinations of three pulps, laminated mold, single layer mold and blended mold (Fig.2,3). The fiber board was cut to $20 \mathrm{~mm} \times 90 \mathrm{~mm} \times 5 \mathrm{~mm}$.

The cut molds were tested for the modulus of rupture (MOR) and modulus of elasticity (MOE) by EZ Test-500 N (Shimadzu Co.) with $80 \mathrm{~mm}$ of span, and 2 $\mathrm{mm} / \mathrm{min}$ of rate following the literature [7], where MOR is static bending strength and MOE is static bending modulus of elasticity. All measurements were achieved for 3 times. The MOE and MOR are represented by the following formulae:

$\operatorname{MOR}(\mathrm{MPa})=3 \mathrm{P} 1 / 2 \mathrm{bh}^{2}$

$\operatorname{MOE}(\mathrm{Pa})=\mathrm{P}_{\mathrm{p}} \mathrm{l}^{3} / 4 \delta \mathrm{bh}^{3}$

, where $\mathrm{P}$ : maximum load $(\mathrm{mN}), \mathrm{P}_{\mathrm{p}}$ : the load at the proportion limit, $\delta$ : the deflection corresponding to $P_{p}$ $(\mathrm{mm}), \mathrm{b}$ : the width $(\mathrm{mm})$, h: the thickness $(\mathrm{mm})$ and $\mathrm{l}$ : the span (mm).

Moreover both specific strength and specific modulus were defined by the following formulae:

Specific strength $\left(\mathrm{MPa} / \mathrm{g}^{-1} \mathrm{~cm}^{3}\right)=\mathrm{MOR} /$ specific gravity

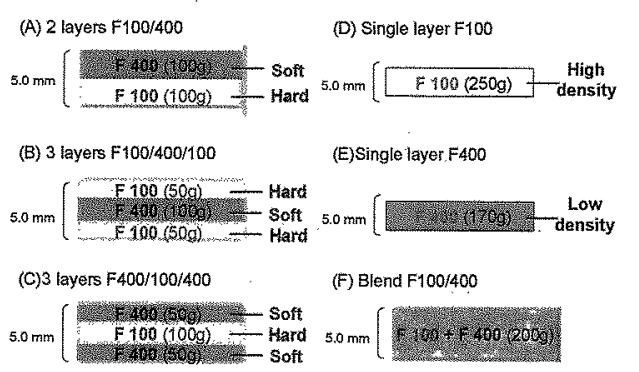

Fig.3 Schematic models for pulp molds. (A) laminated 2 layers $F$ (freeness) $100 / 400$, (B) laminated 3 layers $\mathrm{F} 100 / 400 / 100$, (C) laminated 3 layers $F 400 / 100 / 400$, (D) single layer $F 100$, (E) single layer F400 and (F) blended F $100 / 400$

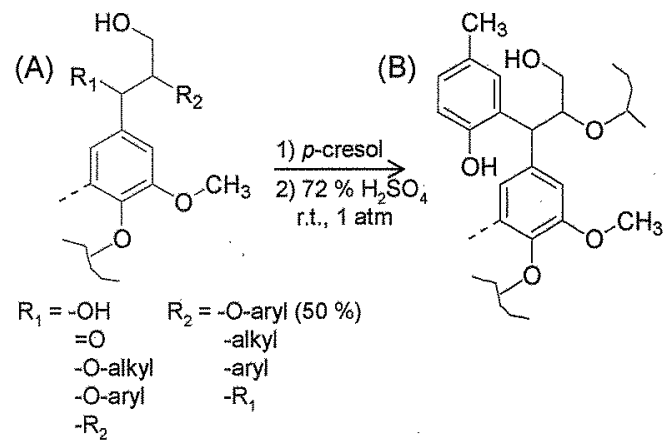

Fig.4 Synthesis of lignophenol ( $p$-cresol type) directly from lignocellulosics. (A) Softwood native lignin in lignocellulosics and (B) lignophenols ( $p$-cresol type).

Specific modulus $\left(\mathrm{GPa} / \mathrm{g}^{-1} \mathrm{~cm}^{3}\right)=$ MOE/specific gravity

\subsection{Synthesis of lignophenols}

Birch (Betula maximowicziana) was selected as a hardwood material. The woody material was milled for 80 mesh passed. Extractives in the material were removed by acetone at room temperature for $72 \mathrm{hrs}$. Lignophenol has been synthesized following the phase-separation system (Fig.4).

Two-step method (process II) was also carried out for $\mathrm{BI}$ as follows [5]. The material $(500 \mathrm{~g})$ was thrown into acetone solution of $p$-cresol with concentration of $3 \mathrm{~mol}$ / phenylpropane units $\left(\mathrm{C}_{9}\right.$ units), which were subunits of native lignin. After evaporation of acetone, $72 \% \mathrm{H}_{2} \mathrm{SO}_{4}$ aq. solution was immersed into the material sorbed by $p$-cresol at $30{ }^{\circ} \mathrm{C}$. Then the mixture was stirred vigorously for $60 \mathrm{~min}$ soon after mixing. After $60 \mathrm{~min}$, the mixture was thrown into $20 \mathrm{~L}$ of de-ionized water with vigorously stirring by a homogenizer for $5 \mathrm{~min}$. Then the purple precipitation was washed until $\mathrm{pH}=5$. After drying the precipitation, lignophenols was extracted by acetone. The lignophenol in acetone was purified by throwing into diethylether (EtOEt) under vigorously stirring in chilled condition. After evaporating and drying on $\mathrm{P}_{2} \mathrm{O}_{5}$, lignophenol was obtained.

\subsection{Characterization of lignophenols}

The structure of lignophenol was characterized by Gel Permeation Chromatography (GPC), ${ }^{1} \mathrm{H}-\mathrm{NMR}$ and Thermal Mechanical Analysis (TMA). GPC was carried out by LC-10 system (Shimadzu Co.) with four columns (KF801, KF802, KF803 and KF804, Shodex Co.), using tetrahydrofuran (THF) after distillation as eluent. $M_{w}$ and $M_{n}$ were determined based on standard polystylene. ${ }^{1} \mathrm{H}-\mathrm{NMR}$ spectrum was measured by JNM-A500 (JOEL Co.) in $\mathrm{CDCl}_{3}$ or $\mathrm{CDCl}_{3} / \mathrm{C}_{5} \mathrm{D}_{5} \mathrm{~N}=3 / 1(\mathrm{v} / \mathrm{v})$. TMA was also carried out by TMA-SS (SII Inc.) in the temperature range $50-280{ }^{\circ} \mathrm{C}$ at $2{ }^{\circ} \mathrm{Cmin}^{-1}$, using penetrating technique for a measurement. UV-Vis spectroscopy was carried out on a UV-560 (JASCO Co.) FT-IR spectroscopy was also carried out on a Spectrum $\mathrm{GX}$ (Perkin Elmer $\mathrm{Co}$.), using the $\mathrm{KBr}$ pellet technique for sample preparation.

2.5 Preparation of pulp mold / lignophenol composite A lignophenol-pulp mold composite was prepared in 
(A) 3 layers $F 100 / 400$

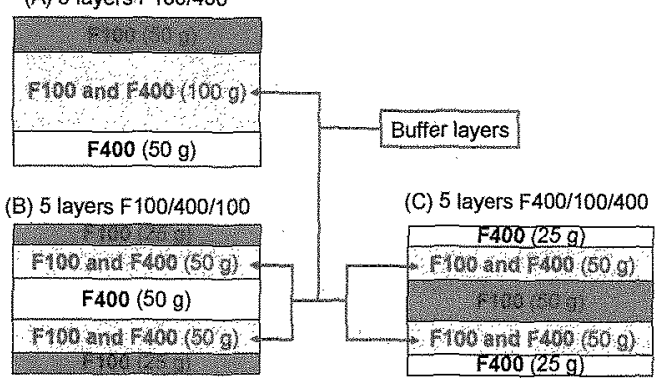

Fig.5 Preparation of graduation structures of laminatae molds including buffer layers. (A) 3 lavers F100/buffer $/ \mathrm{F} 400$, (B) 5 layers F100/ buffer / F400/buffer / F100 and (C) 5 layers F400/buffer / F100 / buffer / F400.Thickness of all molds were $5.0 \mathrm{~mm}$. Buffer layers were blends of $F 100$ and $F 400(50 / 50, w / w)$.

acetone solution (10.95\%). Birch-lignophenol ( $p$-cresol type, $M_{w}=6410, D=2.41$ ) was used. The cut pulp mold was immersed into the lignophenol solution. After evaporation, strength of the composites was tested by Ez-test (Shimadzu Co.).

\subsection{Swelling test}

The mold ( $20 \mathrm{~mm} \times 20 \mathrm{~mm} \times 5 \mathrm{~mm}$ ) was placed on SUS net. The mold was sunk to water at $30 \mathrm{~mm}$ from bottom of a beaker. After $60 \mathrm{~min}$, weight and size of the mold was measured.

\subsection{Laminated mold with buffer layer}

As shown in Fig.5, laminated mold with buffer layer was prepared by combination of three different pulps, F100, F400 and blend of F100 and F400 (50/50, w/w). The resulting mold was tested the strength.

\section{RESULTS AND DISCUSSION}

\subsection{Physical properties}

Fig.6 illustrated the physical properties of pulp molds (control) and lignophenol composites. Both control and composites showed same tendency on both MOR and MOE. Although the molds were made under no heat and no pressures, the control molds of 3 layers F100/400/100
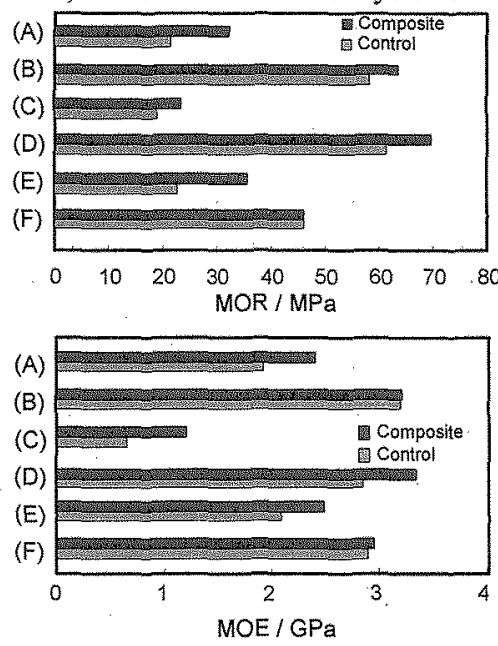

Fig.6 Modulus of ruptures (MOR) and Modulus of elasticity (MOE) of pulp molds and lignophenol composites. (A) 2 layer F $100 / 400$, (B) 3 layers F 100/400/100, (C) 3 layers F 400/100/400, (D) single layer F100, (E) single layer F400 and (F) blended mold F100/400. Lignophenol was Birch-lignophenol ( $p$-cresol type). and single layer F100 showed especially high MOR reached about $60 \mathrm{MPa}$ (Fig.5 B, D). These values were equal to other woody materials enforced by resins [8-11]. All of pulp molds were enforced by lignophenol. The best MOR values reached to $70 \mathrm{MPa}$. Moreover, MOE values also reached about $3.3 \mathrm{GPa}$ which were equal to a fiber board [10].For example, binder less fiber board [9], fiber board with urea-formaldehyde resin [10], paper molds with lignin-phenol resin [12] showed 52, 46 and 60-100 MPa of MOR, respectively. In this way, these pulp molds and lignophenol composites showed practical strength.

Recently these woody materials enforced by resin such as phenolic, melamine, urea, urethane and epoxy resin, have been developed for "recycled materials". However recyclability and sustainability in eco-system on the earth of woody components were inactive because the properties were rigidly fixed by resins. Although these materials can use for a long time to keep high strength, woody components are got out of carbon circulation on the earth. Moreover VOCs problems especially chemical hazards of HCHO have been paid a lot of attentions for phenol, melamine and urea resin. Therefore the most attractive properties of the pulp molds and lignophenol composites were easy separation and high recyclability without VOCs from productions.

The influences of freeness were clearly reflected on MOR but MOE such as difference single layer F100 from F400. Since the BET surface areas of F100 and F400 were 3.04 and $2.11 \mathrm{~m}^{2} \mathrm{~g}^{-1}$, interactions of $\mathrm{F} 100$ will become stronger than F400. Therefore MOR was probably influenced by frequency of interaction. On the other hand, MOE will be influenced mainly interactions on the surface because 3 layers $\mathrm{F} 400 / 100 / 400$ showed small value.

Furthermore, influences of lamination were reflected specific values. For example, on the comparison of the 3 layers F100/400/100 to single layer F100, Both MOR and $\mathrm{MOE}$ of the 3 layers were smaller than single layer. But the specific force and the specific modulus of 3 layers with $0.79 \mathrm{gcm}^{-3}$ of density were $73.4 \mathrm{MPa} / \mathrm{cm}^{3} \mathrm{~g}^{-1}$ and $4.07 \mathrm{GPa} / \mathrm{cm}^{3} \mathrm{~g}^{-1}$, respectively. These values were larger than those of single layer with $1.06 \mathrm{gcm}^{-3}$ of density, $58.7 \mathrm{MPa} / \mathrm{cm}^{3} \mathrm{~g}$ and $2.87 \mathrm{GPa} / \mathrm{cm}^{3} / \mathrm{g}$, respectively. Moreover, blended mold F100/400 with $0.81 \mathrm{gcm}^{-3}$ of density also showed high specific force and modulus, $56.7 \mathrm{MPa} / \mathrm{cm}^{3} \mathrm{~g}$ and $3.56 \mathrm{GPa} / \mathrm{cm}^{3} / \mathrm{g}$, respectively. These results showed both mold with laminated layers and blended mold were expected to be

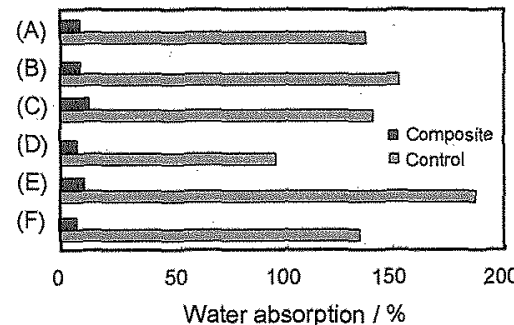

Fig. 7 Water adsorption of pulp molds and lignophenol composites. (A) 2 layer F 100/400, (B) 3 layers F 100/400/100, (C) 3 layers $F$ $400 / 100 / 400$, (D) single layer $F 100,(E)$ single layer $F 400$ and (F) blended mold F100/400. Lignophenol was Birch-lignophenol (pcresol type). 
applied as light and strong materials.

\subsection{Water adsorption}

Fig. 7 showed results of water adsorption tests for the pulp molds and lignophenol composites. All pulp molds showed high water adsorption. A part of the molds were destroyed by swelling. However, all lignopheno composites showed dramatically high hydrophobicity. As these results showed, cellulose fibers were covered by lignophenol in acetone solutions. These structures were mimicked those of lignocellulosics. As lignin protects cell wall by its hydrophobicity, lignophenol prevents water from approaching to pulp. Although both 3 layers F400/200/400 and single layer F400 composed of lignophenol showed relatively high adsorption, because of roughness of the surface observed by Scanning Electron Microscopy (Fig.2). Since these interactions were reversible, lignophenols were recycled easily and perfectly from the composites without damages. Therefore these composites are expected to be used as recyclable materials.

\subsection{Laminated molds with buffer layer}

To produce easily more stable and stronger molds, preparation method was improved. Since parts of laminated molds showed detachment on the surface of different freeness (F100 and F400), buffer layers which composed of blend of F100 and F400 (50/50, w/w) were added on these surfaces (Fig.5). In order to observe cross sections after bending tests, only pulp molds were tested. Fig. 8 clearly demonstrated that it was effective to reinforce the strength of the pulp mold. Especially both 3 layered and 5 layered F400/buffer/F100/buffer/F400 were especially reinforced for 2.5-3.0 times. As shown in Fig. 9, without buffer layers clear de-laminations were observed at the cross sections after bending tests. On the other hands, gradating structures were observed with buffer layers. The gradating structures will contribute to prevent detachments on the surfaces of layers. Moreover the gradating structures also decreased stress on the surfaces with affinities each other. Therefore both strength and stability of these molds increased dramatically. But only 5 layer F100 / buffer / F400 / buffer / F100 showed slightly improvement of strength. Since hard-soft-hard type structures will naturally
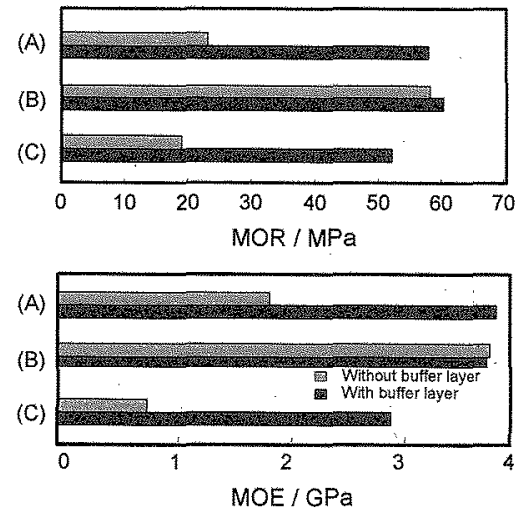

Fig. 8 Modulus of ruptures (MOR) and Modulus of elasticity (MOE) of pulp molds with and without buffer layers. (A) 3 layer F100/buffer/F400, (B) 5 layers F100/buffer / F400 / buffer / F100, (C) 5 layers $F 400 /$ buffer / F100/ buffer / F400.

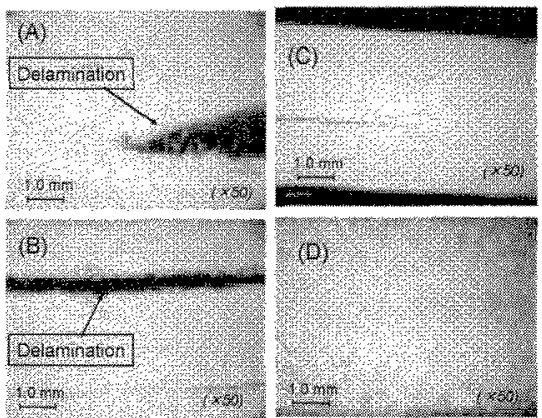

Fig.9 Microscope photographs of laminated molds after bending test. (A) layers F400/F $100 / F 400$, (B) 3 layers F100/F400/F100, (C) 5 layers F400 huffer $/ F 100$ /buffer $/ F 400$ and (D) 5 layers F100 buffer $/ F 400$ /buffer $/ F 100$ F represented freeness of pulp.

produce high strength, 3 layer F100 / F400 / F100 showed high strength without buffer layer. As shown in Fig.6, a close surface with small freeness will contribute high strength of the molds. Moreover, water adsorptions of all molds with buffers are almost equal to other pulp molds (data not shown). Therefore it will be useful for these new molds to be reinforced with lignophenol.

\section{CONCLUSION}

The pulp molds made from recycled papers showed practical strength. As decrease freeness of pulp, resulting pulp mold showed high strength because of abundant hydrogen bonds between fibers. The molds of blended pulp and laminated layers showed higher specific force and specific modulus than single layer molds. This indicated that it is capable to design strength of the mold for purposes. The compositions of pulp molds and hydrophobic lignophenol produced water resistant composites. Moreover, the composites became stronger than pulp mold because of coagulation forces of lignophenol. Laminated pulp molds with buffer layers were largely reinforced by increasing gradation structures and decreasing stresses on the surfaces between two fiber layers with different freeness. Designing for combinations of pulp freeness, various applications on demands are expected.

\section{REFERENCES}

[1] JIS P 8121

[2]M. Funaoka and I. Abe, Tappi., 72(8), 145-149 (1989).

[3]M. Funaoka, M. Matsubara, N. Seki, S. Fukatsu, Biotechnology and Bioengineering, 46, 545-552(1995)

[4]M. Funaoka, S. Fukatsu, Holzforshung, 50, 245-257(1996)

[5]M. Funaoka, Polym. Int., 47, 277-290(19.98)

[6]M. Funaoka, Macromol. Symp., 201, 213-221(2003)

[7] JIS A 1408

[8]T-H. Yang, C-J. Lin, S-Y. Wang, M-J. Tsai, Building and Environment, 42, 189-195(2007)

[9]J. A. Velasquez, F. Ferrando, J. Salvado, Industrial Crops and Products, 18, 17-23(2003)

[10]C. Felby, J. Hassingnoe, M. Lund, Enzyme and Microbial. Technology, 31, 736-741(2002)

[11]W. D. Wanrosli, Z. Zainuddin, S. Roslan, Industrial Crops and Products, 21, 325-329(2005)

[12]J. Nemoto, Y. Uraki, Y. Sano, Mokuzai Gakkaishi, 49(4), 287-292 (2003) 